\title{
Silencing of Girdin suppresses the malignant behavior of colorectal carcinoma cells
}

\author{
JIA LU ${ }^{1,2}$, LIN ZHANG ${ }^{1,2}$, HONGYAN ZHOU ${ }^{2}$, ZHENWU DU $^{1}$ and GUIZHEN ZHANG ${ }^{1}$ \\ ${ }^{1}$ Central Laboratory, The Second Hospital of Jilin University, Changchun, Jilin 130041; \\ ${ }^{2}$ Department of Ophthalmology, China-Japan Union Hospital of Jilin University, Changchun, Jilin 130033, P.R. China
}

Received January 3, 2018; Accepted June 13, 2018

DOI: 10.3892/or.2018.6511

\begin{abstract}
The aim of the present study was to investigate the effect of the actin-binding protein Girdin on the proliferation, invasion and migration of colorectal cancer (CRC) cells. Cultured CRC cells (LoVo cell line) were transfected by Girdin-specific and control shRNA constructs and analyzed for proliferation, invasion and migration by the MTT, Transwell and wound-healing assays, respectively. The activation of the Janus kinase/signal transducer and activator of transcription (JAK/STAT) signaling pathway and expression of proinflammatory cytokines was examined by western blotting and ELISA assay, respectively. The effect of Girdin silencing on CRC growth was also evaluated in a xenograft model using nude mice, which were subcutaneously injected with Girdin-deficient and negative control LoVo cells and analyzed for tumor volume and weight. Transfection of LoVo cells with Girdin-specific shRNA inhibited Girdin mRNA expression to $27.5 \%$ and protein expression to $36.7 \%$ when compared with expression levels in the control cells $(\mathrm{P}<0.001)$ and significantly demonstrated suppression of LoVo cell proliferation $(\mathrm{P}<0.05)$, invasion $(\mathrm{P}<0.01)$ and migration $(\mathrm{P}<0.01)$. Furthermore, Girdin silencing downregulated the phosphorylation of the signaling proteins JAK (by 42\%, $\mathrm{P}<0.001$ ) and STAT3 (by $34 \%, \mathrm{P}<0.01$ ) and the content of IFN (by $28 \%$, $\mathrm{P}<0.001$ ) and IL-6 (by 44\%, $\mathrm{P}<0.001$ ) compared to the control. Notably, inhibition of Girdin expression effectively suppressed tumorigenicity of LoVo cells in vivo as evidenced by the reduced volume $(\mathrm{P}<0.05)$ and weight $(\mathrm{P}<0.05)$ of the tumors derived from Girdin shRNA-transfected LoVo cells compared to those from the control cells. In conclusion, the silencing of Girdin expression inhibited the malignant behavior of CRC cells via the downregulation of the JAK/STAT signaling pathway, indicating Girdin as a potential therapeutic target in CRC. In the present study, we revealed, for the first time, that
\end{abstract}

Correspondence to: Professor Guizhen Zhang, Central Laboratory, The Second Hospital of Jilin University, 18 Ziqiang Street, Changchun, Jilin 130041, P.R. China

E-mail: zhangguizhenjlu@163.com

Key words: colorectal cancer, Girdin, proliferation, migration, invasion the malignant behavior of CRC cells depended on the expression of an actin-binding protein, Girdin. Silencing of Girdin expression by specific shRNA suppressed the proliferation, invasion, and migration of CRC cells through the decrease in proinflammatory cytokines IFN and IL-6 and the downregulation of the JAK/STAT signaling pathway. Our findings indicated that Girdin expression may be a potential novel therapeutic target in CRC.

\section{Introduction}

Colorectal cancer (CRC) is one of the most common types of malignancy and the leading cause of death among all digestive cancers worldwide $(1,2)$. According to the world cancer statistics, the incidence and mortality of CRC are increasing every year $(3,4)$. The data of the last decade indicate that the prognosis of advanced CRC is usually not favorable, even after surgery, combination chemotherapy and targeted agent treatment (5-7). Studies have shown that CRC-related mortality is largely caused by tumor metastasis $(8,9)$, a complicated multistep process based on the ability of tumor cells to migrate to and invade other organs $(10,11)$. Metastasis is an important adverse factor in the treatment and prognosis of CRC (12); however, the molecular mechanisms underlying CRC spread remain largely unknown.

Accumulating evidence indicates that the Januskinase/signal transducer and activator of transcription (JAK/STAT) pathway plays an important role in the development of a number of human cancers (13), including CRC (14), breast cancer (15) and hepatocellular carcinoma (16). The JAK/STAT signaling pathway is involved in various physiological processes such as immune function and the growth, invasion and migration of cancer cells $(17,18)$. JAK/STAT signaling could be activated by cytokines such as interleukin-6 (IL-6), IL-10 and interferons (IFNs), which induce receptor dimerization, and trigger the downstream signaling cascade including activation of the associated JAKs, and phosphorylation and translocation of STATs to the nucleus where they upregulate transcription of target genes (16). Recently, it has been demonstrated that constitutive activation of JAK/STAT signaling is involved in the development of CRC through stimulation of tumor cell growth, survival, invasion and migration $(19,20)$. These findings demonstrate the crucial importance of the JAK/STAT pathway in CRC initiation and progression. 
Girdin is a novel multi-functional protein acting at the cross-roads of $\mathrm{G}$ protein- and tyrosine kinase receptor-mediated signaling (21), which has been shown to be involved in diverse biological processes, including cancer cell proliferation and spread, in particular through the activation of STAT3 (22-24). An increasing number of studies have demonstrated that Girdin is highly expressed in several types of cancers, including breast cancer (25), glioma (26), lung (27) and gastric cancer (28). In CRC, Girdin was shown to promote chemoresistance (29); however, the association between Girdin and CRC development remains to be elucidated. The present study aimed to clarify the effects of Girdin on CRC cell proliferation, migration and invasion through downregulation of the expression of Girdin using shRNA.

\section{Materials and methods}

Cell culture. Human CRC cell lines Caco-2, LoVo and HCT-15 were purchased from the Shanghai Cell Bank, Type Culture Collection Committee, Chinese Academy of Sciences (Shanghai, China). Cells were cultured in Dulbecco's modified Eagle's medium (DMEM; Gibco; Thermo Fisher Scientific, Inc., Grand Island, NY, USA) supplemented with $10 \mathrm{ml} / 1$ fetal bovine serum (FBS; Gibco; Thermo Fisher Scientific, Inc.), in a humidified atmosphere of $5 \mathrm{ml} / 1 \mathrm{CO}_{2}$ at $37^{\circ} \mathrm{C}$. Cells in the exponential phase were used for experiments.

Girdin silencing in CRC cells. shRNA expression constructs containing Girdin shRNA(Girdin-pGCH1/Neo) and non-targeting control (NC) shRNA (NC-pGCH1/Neo) were used in the experiments (30). The sequence of Girdin shRNA was 5'-GATCCCCGTCAATAATGATGCCTCACTTCA AGAGAGTGAGGCATCATTATTGACTTTTT-3' and that of NC shRNA was 5'-GATCCCCTTCTCCGAACGTGT CACGTTTCAAGAGAACGTGACACGTTCGGAGAATTT

TT-3' (30) (Auragene Bioscience, Co., Changsha, China). LoVo cells with high Girdin expression were transfected with Girdin-pGCH1/Neo or NC-pGCH1/Neo using Invitrogen ${ }^{\mathrm{TM}}$ Lipofectamine 2000 (Thermo Fisher Scientific, Inc.) according to the manufacturer's protocol. Twenty-four hours after transfection, clones with stable shRNA expression were selected with $200 \mu \mathrm{g} / \mathrm{ml} \mathrm{G} 418$ (Invitrogen; Thermo Fisher Scientific, Inc.) for over a week and identified. The following experimental groups were used: The LoVo group (untransfected cells), the NC group (NC-pGCH1/Neo-transfected cells) and the Girdin-shRNA group (Girdin-pGCH1/Neo-transfected cells). For inhibitor interference experiments, NC or Girdin shRNA cells were cultured in complete medium containing $10 \mathrm{nmol} / 1$ LY2784544 (Shanghai ZZBIO Co., Ltd., Shanghai, China) or an equal volume of dimethyl sulfoxide (DMSO) for $48 \mathrm{~h}$.

Real-time polymerase chain reaction (RT-PCR). Total mRNA from cultured cells was extracted with TRIzol (Tiangen Biotech, Beijing, China) according to the manufacturer's protocol and used to obtain cDNA by reverse transcription. The primers for Girdin- and $\beta$-actin-encoding genes $C C D C 88 A$ and $A C T B$, respectively were as follows: $C C D C 88 A$ sense, 5 '-CTC CAGGCATGAAGCGAACA-3' and antisense, 5'-TGGCAG AGCGAGCATCCGA-3'; ACTB sense, 5'-CTTAGTTGCGTT
ACACCCTTTCTTG-3' and antisense, 5'-CTGTCACCTTCA CCGTTCCAGTTT-3'. Quantitative analysis was performed using SYBR-Green Master Mix (Tiangen Biotech) in an Exicycler $^{\mathrm{TM}} 96$ quantitative fluorescence analyzer (Bioneer Corporation, Daejeon, Korea) and relative mRNA expression of the $C C D C 88 A$ gene was calculated after normalization to that of $A C T B$.

Western blotting. Cultured cells were lysed by NP-40 lysate (Beyotime Institute of Biotechnology, Haimen, China) and protein concentration was determined by the BCA assay (Beyotime Institute of Biotechnology). Total proteins from each sample $(40 \mu \mathrm{g})$ were separated under denaturing conditions in a $10 \%$ sodium dodecyl sulfate polyacrylamide gel electrophoresis (SDS-PAGE) and electro-transferred to a polyvinylidene fluoride (PVDF) membrane (EMD Millipore, Bedford, MA, USA). After blocking, the membrane was incubated with primary antibodies which dilution with $5 \%$ skim milk in TBS containing $0.1 \%$ Tween-20 against Girdin (cat. no. ab179481), JAK (cat. nos. ab108596 and ab227016), STAT3 (cat. nos. ab119352 and ab76315), or $\beta$-actin (cat. no. ab8227) (1:1,000; all were from Abcam, Shanghai, China) at $4^{\circ} \mathrm{C}$ overnight and then, with a horseradish peroxidase (HRP)-labeled secondary antibody (cat. no. BS13278) which dilution with 5\% skim milk in TBS containing $0.1 \%$ Tween-20 (Bioword, Dublin, OH, USA) at room temperature for $45 \mathrm{~min}$. Immune complexes were visualized using ECL reagents and relative protein expression was assessed by densitometry using the Gel-Pro-Analyzer software 4.5 (Media Cybernetics, Inc., Rockville, MD, USA).

Cell proliferation assay. Cells were seeded in 96-well microtiter plates at a density of $2 \times 10^{3} /$ well in $200 \mu \mathrm{l}$ of DMEM with $10 \mathrm{ml} / 1 \mathrm{FBS}$ and allowed to adhere. After 12, 24, 48, 72 or $96 \mathrm{~h}, 0.2 \mathrm{~g} / \mathrm{ml}$ 3-(4,5-dimethylthiazol-2-yl)-2,5-diphenyltetrazolium bromide (MTT; Sigma-Aldrich; Merck KGaA, Darmstadt, Germany) was added to each well for $4 \mathrm{~h}$ at $37^{\circ} \mathrm{C}$. Cell growth was assessed by measuring the optical density (OD) at $490 \mathrm{~nm}$ using a microplate reader ELX-800 (BioTek Instruments, Inc., Winooski, VT, USA).

Cell migration assay. Cell migration was determined using a wound healing assay. Cells were seeded in a 6 -well plate in DMEM with $10 \mathrm{ml} / 1 \mathrm{FBS}$ at a density of $1 \times 10^{5} /$ well, cultured to $>95 \%$ confluence, and then a wound (a) was inflicted on the cell monolayer using a $200-\mu 1$ pipette tip. Cells were further cultured for 12 or $24 \mathrm{~h}$ and then observed and imaged under a fluorescent inverted microscope (YG-2000; Olympus Corp., Tokyo, Japan), and the migration distance (b) was determined, and the cell migration rate $=\mathrm{b} / \mathrm{a}$.

Transwell invasion assay. For each group, $2 \times 10^{4}$ cells were collected, resuspended in $200 \mu 1$ of serum-free DMEM, and seeded into the upper chamber of a Transwell plate (Corning Life Sciences, Tewksbury, MA, USA), pre-coated with Matrigel (BD Biosciences, San Jose, CA, USA). The lower chamber contained $800 \mu \mathrm{l}$ of DMEM supplemented with $30 \mathrm{ml} / \mathrm{l} \mathrm{FBS}$. Plates were incubated for $24 \mathrm{~h}$ at $37^{\circ} \mathrm{C}$ and then, cells on the upper surface of the microporous membrane were wiped off with a cotton swab, and the cells that invaded the 

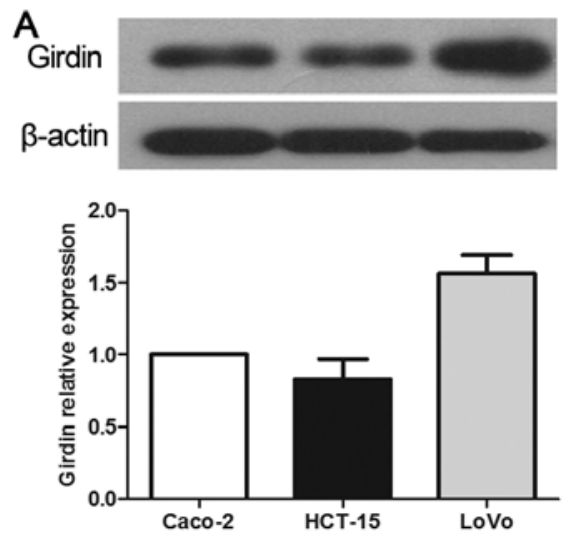
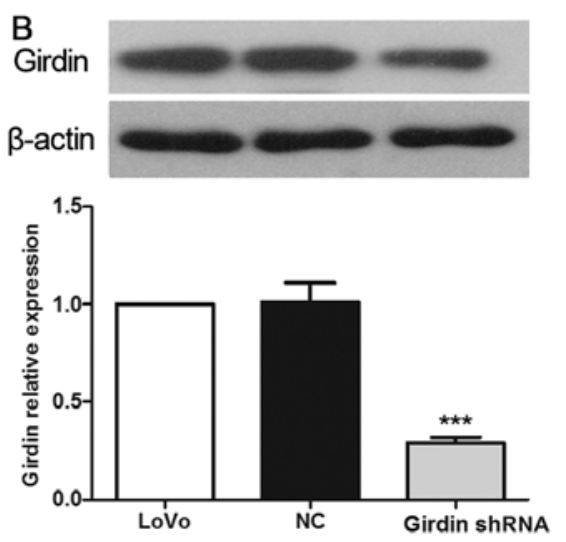

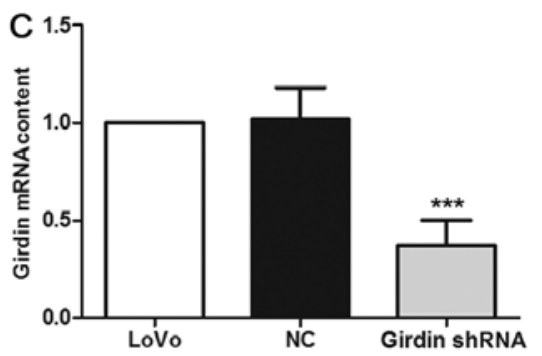

Figure 1. Expression of Girdin is inhibited by specific shRNA. (A) Girdin expression in CRC cells was assessed by western blotting. (B and C) LoVo cells were transfected with non-targeting control shRNA (NC) or Girdin shRNA (Girdin shRNA) and analyzed for protein expression by (B) western blotting and (C) real-time PCR. $\beta$-actin was used as an internal control. Representative images of three independent experiments are shown; the data are presented as the mean $\pm \mathrm{SD} ;{ }^{* * *} \mathrm{P}<0.001$ compared with $\mathrm{NC}$.

lower surface were fixed with paraformaldehyde and stained with crystal violet. Cells were counted under an inverted microscope (YG-2000; Olympus) (magnification, $x 200$ ) in five fields and the average number of invaded cells was calculated.

ELISA. ELISA kits (Uscn Life Science Inc., Wuhan, China) were used to detect INF- $\gamma$ and IL-6 levels in mouse colon tissues and cells. Procedures were conducted in strict accordance with the kit instructions.

In vivo experiments. Fifteen BALB/c nude mice $(20 \mathrm{~g}$, 4-6 weeks of age) were purchased from the Animal Center of Jilin University and maintained under pathogen-free conditions at $22^{\circ} \mathrm{C}$ and $40-50 \%$ humidity, with a 12-h light/dark cycle and ad libitum access to food and water. Mice were inoculated subcutaneously into the right breast pad with $1 \times 10^{6}$ of $\mathrm{NC}$ or Girdin shRNA LoVo cells suspended in $0.2 \mathrm{ml}$ normal saline, and tumor size was assessed with calipers every 3 days over a 30-day period. Tumor volume $\left(\mathrm{mm}^{3}\right)$ (smaller than $\left.2 \mathrm{~mm}^{3}\right)$ was determined using the formula: (width) ${ }^{2} \mathrm{x}$ length. The mice were decapitated after 30 days and tumor weight was measured. The animal care and treatment protocols were approved by the Experimental Animal Ethics Committee of Jilin University.

Statistical analysis. The data were processed using the GraphPad Prism 5.0 software (GraphPad Software, Inc., San Diego, CA, USA) and presented as the mean \pm standard deviation (SD). Comparisons between groups were performed using one-way analysis of variance (ANOVA), and multiple comparisons were performed using Bonferroni post hoc test. $\mathrm{P}<0.05$ was considered to indicate a statistically significant difference.

\section{Results}

Expression of Girdin in CRC cell lines and its inhibition by shRNA. Among the human CRC cell lines used in this study, LoVo cells exhibited the highest expression of Girdin, as evidenced by western blotting assessment of the protein expression (Fig. 1A). Therefore, we chose the LoVo cell line for further experiments. Transfection with Girdin-specific shRNA resulted in significant inhibition of Girdin protein expression in LoVo cells, which constituted only $36.7 \%$ of that in the NC group (Fig. 1B, $\mathrm{P}<0.001$ ). These results were further confirmed by RT-PCR, which revealed that the expression of $C C D C 88 \mathrm{~A}$ mRNA in the Girdin shRNA group was $27.5 \%$ of that in the NC group (Fig. 1C, $\mathrm{P}<0.001$ ).

Girdin inhibition suppresses LoVo cell proliferation, invasion and migration. The effect of CCDC $88 A$ mRNA silencing on the functional characteristics of CRC cells was assessed by cell proliferation, migration and invasion assays. The results indicated that Girdin-deficient cells demonstrated a significantly slower proliferation rate compared with the NC cells (Fig. 2A, $\mathrm{P}<0.05)$ and reduced invasion ability as evidenced by a significantly lower number of cells that penetrated the Transwell membrane: $36.0 \pm 4.74$ compared to $86.4 \pm 8.62$ in the NC group (Fig. 2B and C; $\mathrm{P}<0.01$ ). Furthermore, the wound healing rate reflecting cell migration was significantly lower in the Girdin-deficient cells at both 12 and $24 \mathrm{~h}$ compared to that in the control cells (Fig. 2D-F; P<0.01). Overall, these data indicated that the reduction of Girdin expression resulted in the inhibition of the proliferation, invasion and migration of CRC cells.

Girdin inhibition downregulates the activation of the JAK/STAT signaling pathway. To investigate the molecular mechanism underlying Girdin-mediated effects on cell migration and invasion, we assessed the activation of the JAK/STAT signaling pathway critically involved in tumor invasion and metastasis. The results revealed that the levels of p-JAK and p-STAT3 were decreased by $42 \%$ (Fig. $3 \mathrm{~A}$ and $\mathrm{B}, \mathrm{P}<0.001$ ) and $34 \%$ (Fig. $3 \mathrm{~A}$ and $\mathrm{C}, \mathrm{P}<0.01$ ), respectively, in Girdin-deficient cells compared to levels in the NC cells. Furthermore, the expression of proinflammatory cytokines IL-6 and IFN which play important roles in tumor physiology, were reduced by 28\% (Fig. 3D, $\mathrm{P}<0.001$ ) and 44\% (Fig. 3E, $\mathrm{P}<0.001$ ), respectively, in the Girdin-deficient cells compared to levels in the NC cells. 

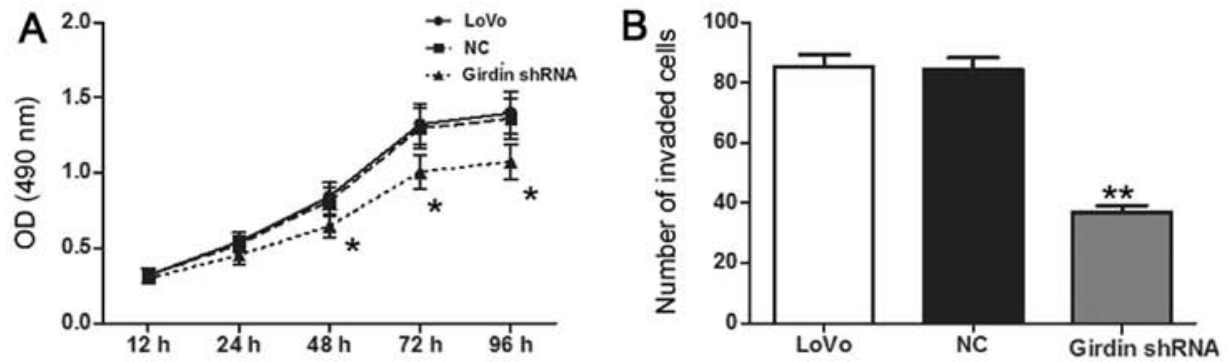

C
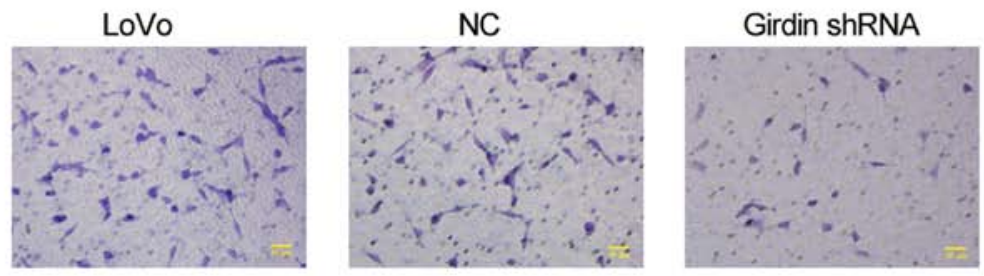

D

$\mathrm{Oh}$

$12 \mathrm{~h}$

$24 \mathrm{~h}$
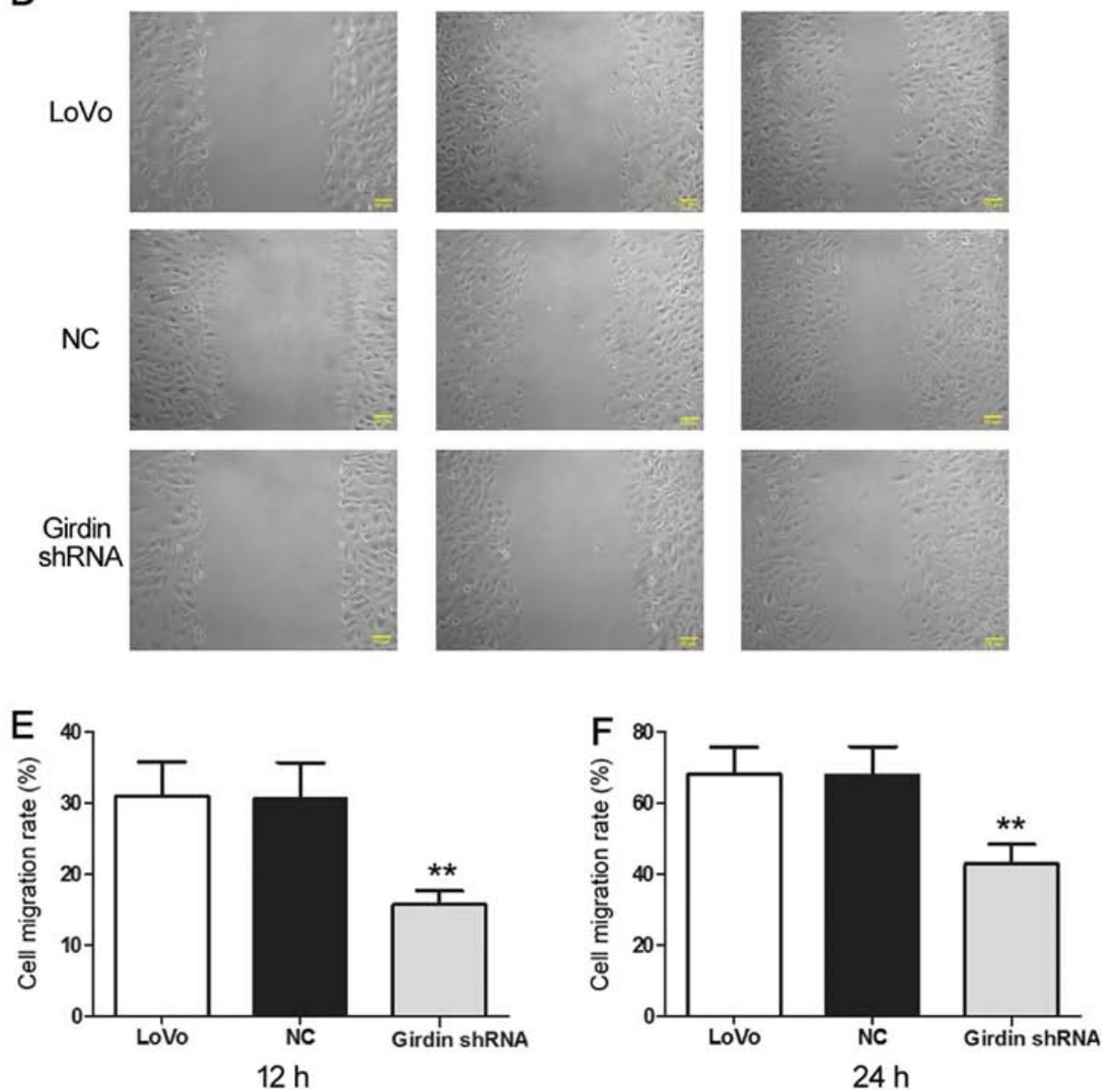

Figure 2. Silencing of Girdin inhibits LoVo cell proliferation, invasion and migration. LoVo cells transfected with non-targeting control shRNA (NC) or Girdin shRNA (Girdin shRNA). (A) Cell proliferation by the MTT assay. (B and C) Cell invasion by the Transwell assay. (D-F) Cell migration by the wound-healing assay. Scale bar, $100 \mu \mathrm{m}$. Representative images of three independent experiments are shown. The data are presented as the mean $\pm \mathrm{SD}$; ${ }^{*} \mathrm{P}<0.05$, ${ }^{* *} \mathrm{P}<0.01$ compared to NC.

As these data indicated that Girdin induced JAK/STAT3 signalinginLoVocells, weexamined whethertheGirdin-mediated effects on CRC cell invasion were mediated through JAK/STAT3 activation. For this purpose, we treated Girdin-deficient and NC cells with a JAK inhibitor LY2784544. As expected, LY2784544 downregulated the phosphorylation of JAK and STAT3 in NC cells, however, it did not affect that in Girdin-deficient cells. Notably, there was no difference in p-JAK and p-STAT3 levels between LY2784544-treated NC cells and Girdin-silenced cells (Fig. 3F-H), suggesting that the inhibition of JAK/STAT signaling by LY2784544 and the inhibition of Girdin expression caused the same downregulation of JAK/STAT activation. 
A

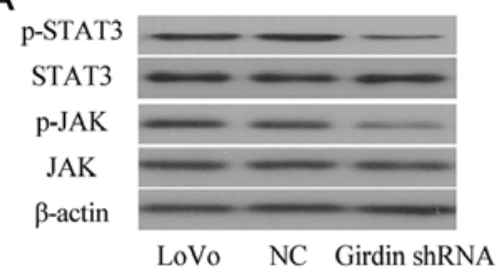

LoVo NC Girdin shRNA
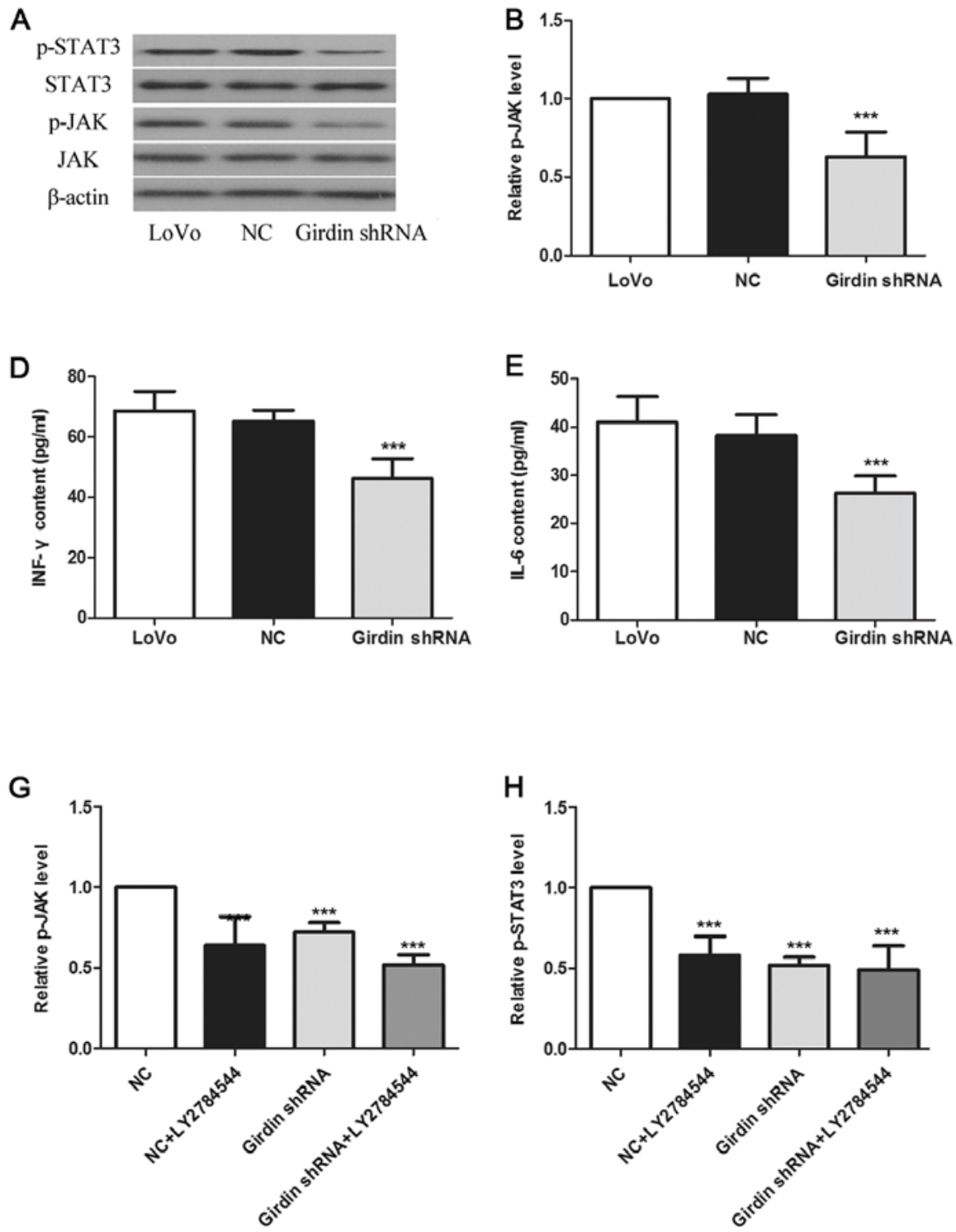

$\mathrm{F}$
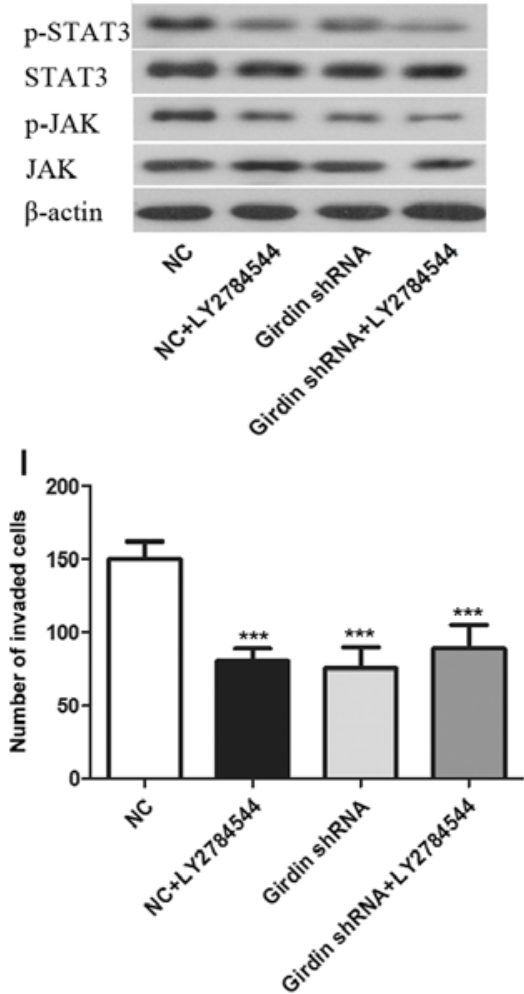

$\mathrm{J}$
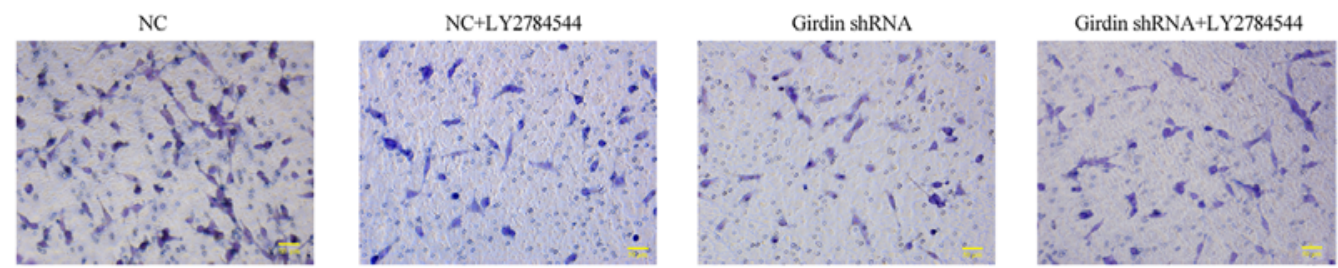

Figure 3. Girdin silencing inhibits the JAK/STAT3 signaling pathway. (A-C) LoVo cells transfected with non-targeting shRNA construct (NC) or Girdin shRNA construct (Girdin shRNA) and analyzed for protein expression by western blotting. (A and B) p-JAK; (A and C) p-STAT3. (D and E) ELISA assay was used for analyzing the content of (D) IFN and (E) IL-6. (F-H) NC and Girdin shRNA-transfected LoVo cells were treated or not with a JAK/STAT inhibitor LY2784544. JAK/STAT activation was analyzed by western blotting. (F and G) p-JAK; (F and H) p-STAT3. (I and J) Cell invasion analyzed by Transwell assay. Representative images of three independent experiments are shown. $\beta$-actin was used as an internal control. The Figure shows the representative results from repeated experiments $(n=6)$. The data are presented as the mean $\pm \mathrm{SD} ;{ }^{* *} \mathrm{P}<0.01,{ }^{* * *} \mathrm{P}<0.001$ compared to NC.

Furthermore, LY2784544 reduced the invasiveness of LoVo cells to a level similar to that of Girdin-deficient cells (Fig. 3I and J). Collectively, these results indicated that Girdin regulates CRC cell behavior through JAK/STAT3 signaling.

Girdin silencing suppresses LoVo growth in vivo. The effects of Girdin on the growth of LoVo cells in vitro were confirmed in vivo using a xenograft mouse model. Nude mice were injected with Girdin-silenced, NC and wild-type LoVo cells and observed for tumor growth for 30 days. At the end of the experiment, tumors were weighed. Xenograft tumors derived from Girdin-silenced cells grew slower compared to those produced by NC and wild-type cells ( $\mathrm{P}<0.05$, Fig. 4A) and were significantly smaller at the endpoint $(\mathrm{P}<0.05$, Fig. $4 \mathrm{~B}$ and $\mathrm{C})$, indicating that Girdin also positively regulated CRC growth in vivo. 

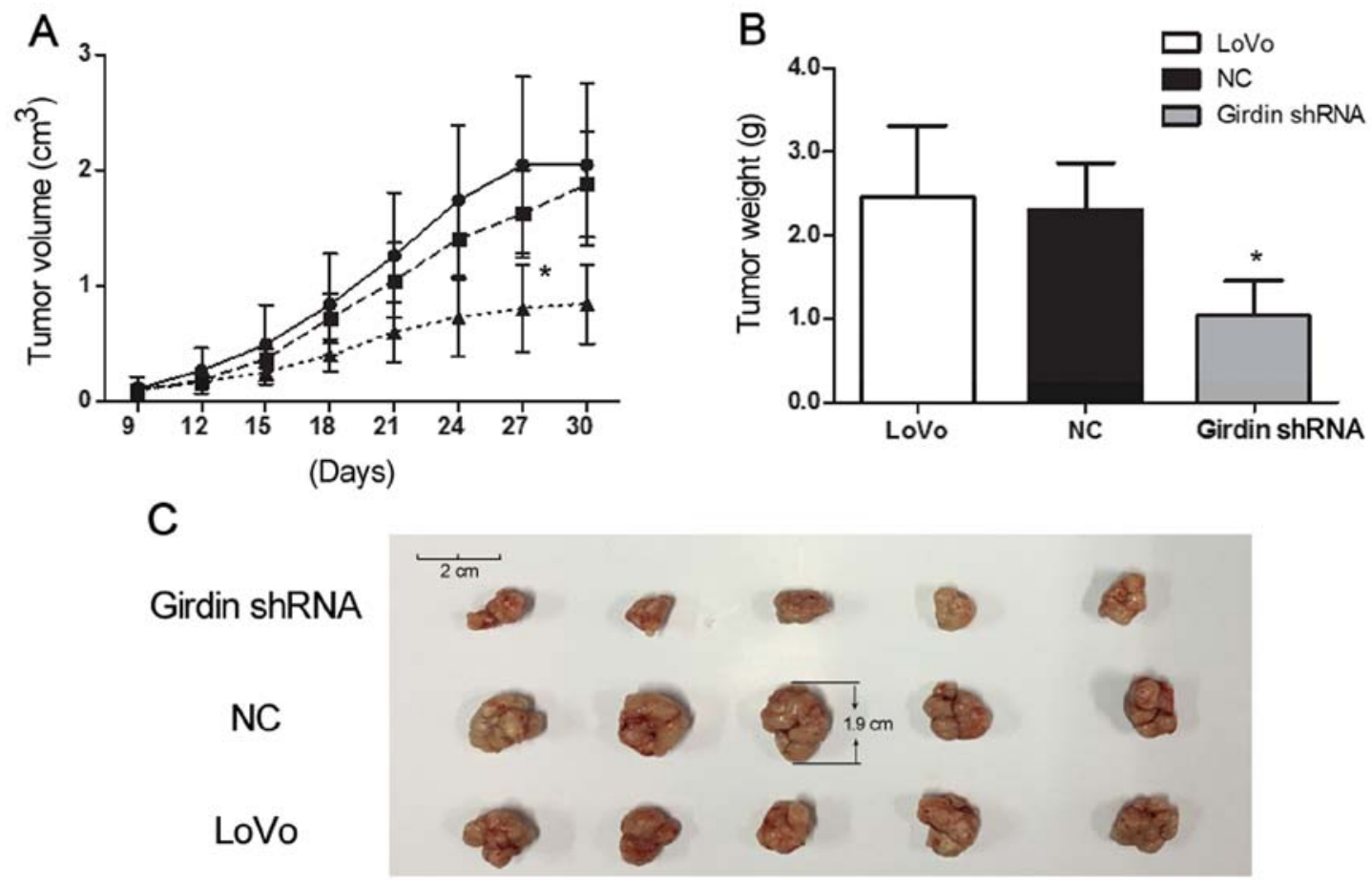

Figure 4. Girdin silencing suppresses LoVo growth in vivo. Wild-type, NC, or Girdin shRNA LoVo cells were subcutaneously inoculated into 4-6 week-old nude mice. (A) Tumor volumes were recorded every three days for 30 days. (B) Tumor weights were assessed after mice were sacrificed at day 30 . (C) Tumor images of each group. The data are presented as the mean $\pm \mathrm{SD}$; ${ }^{*} \mathrm{P}<0.05$ compared to NC.

\section{Discussion}

Girdin is an actin-binding protein and its expression is associated with the initiation and progression of many types of tumors, thus presenting a new target in the diagnosis and treatment of cancer. Previous studies have demonstrated that Girdin silencing enhances the chemosensitivity of CRC (29) and radiosensitivity of hepatocellular carcinoma (31). Jin et al (25) found that Girdin could regulate the biological behavior of breast tumors, whereas Wang et al (28) showed that Girdin plays an important role in gastric cancer development and metastasis. The present study demonstrated that Girdin is expressed at high levels in CRC cells and is associated with their malignant behavior through the activation of the JAK/STAT signaling pathway.

Proliferation, migration and invasion of tumor cells are the main biological characteristics of malignant cancers, defining tumor growth and spread and, ultimately, disease prognosis (32). Girdin is highly expressed in a variety of malignant tumors, including glioma and breast, colon and lung cancers (25-28), where it can promote proliferation, migration and invasion of tumor cells (22). In the present study, we found that the downregulation of Girdin expression in LoVo cells could inhibit cell proliferation, migration and invasiveness, indicating the critical role of Girdin in CRC, which is consistent with previous studies.

We also addressed the molecular mechanism underlying Girdin-mediated effects on CRC cell behavior and found that Girdin induced the activation of the JAK/STAT signaling pathway and promoted the expression of proinflammatory cytokines IL-6 and IFN. STAT3 is a key signaling molecule in the JAK/STAT pathway, which has been validated as a potential target for cancer therapy as it promotes the transcription of cancer-related genes through transduction of external signals from surface receptors to the nucleus (33). JAK/STAT signaling is activated by several cytokines such as IFN, IL-10 and IL-6, thus contributing to inflammation and carcinogenesis $(18,34)$. Increasing evidence demonstrates that phosphorylation-dependent activation of JAK/STAT triggers neoplasm invasion and metastasis $(35,36)$. Thus, pronounced activation of JAK/STAT signaling was detected in CRC tissues (14). In the present study, JAK/STAT activation in CRC cells was downregulated both by Girdin shRNA and a specific JAK/STAT inhibitor, which was correlated with the suppression of CRC cell invasion, indicating that Girdin promoted malignant behavior of CRC through JAK/STAT signaling. Notably, CRC-promoted activity of Girdin was confirmed in vivo as Girdin-deficient LoVo cells were much slower than NC cells in tumor formation upon transplantation to nude mice, indicating that application of Girdin shRNA can delay CRC progression. These results indicated that Girdin may regulate CRC growth and spread through the JAK/STAT pathway and that Girdin should be investigated as a novel therapeutic and diagnostic target in CRC.

In conclusion, the results of the present study revealed that the downregulation of the expression of Girdin can inhibit the proliferation, invasion and migration of CRC cells through decrease in proinflammatory cytokine production and inhibition of JAK/STAT signaling. Our study provides preliminary clarification of the role of Girdin in the malignant potential of CRC, indicating Girdin as a potential target for gene therapy in CRC and other cancers. Whether overexpression of Stat 3 in CRC cell lines could effectively reverse the effects of Girdin knockdown on cell invasiveness warrants further research. 


\section{Acknowledgements}

Not applicable.

\section{Funding}

The present study was supported by the HEMA Soft Hydrophilic Contact Lens Development and Clinical Safety Evaluation 3 (3R217BP73430).

\section{Availability of data and materials}

The datasets used during the present study are available from the corresponding author upon reasonable request.

\section{Authors' contributions}

GZ was the overall instructor of the study, she formulated the experiment plan and determined the accuracy of the experimental results; JL was responsible for the experiment and operation; LZ, HZ and ZD provided experimental and operational support. All authors read and approved the manuscript and agree to be accountable for all aspects of the research in ensuring that the accuracy or integrity of any part of the work are appropriately investigated and resolved.

\section{Ethics approval and consent to participate}

The animal care and treatment protocols were approved by the Experimental Animal Ethics Committee of Jilin University.

\section{Patient consent for publication}

Not applicable.

\section{Competing interests}

The authors declare that they have no competing interests.

\section{References}

1. Ahmad R, Alam M, Hasegawa M, Uchida Y, Al-Obaid O, Kharbanda S and Kufe D: Targeting MUC1-C inhibits the AKT-S6K1-elF4A pathway regulating TIGAR translation in colorectal cancer. Mol Cancer 16: 33, 2017.

2. Wang C, Yue Y, Shao B, Qiu Z, Mu J, Tang J, Han X, Xiang T and Ren G: Dickkopf-related protein 2 is epigenetically inactivated and suppresses colorectal cancer growth and tumor metastasis by antagonizing Wnt/ $\beta$-catenin signaling. Cell Physiol Biochem 41: 1709-1724, 2017.

3. Chen W, Zheng R, Baade PD, Zhang S, Zeng H, Bray F, Jemal A, Yu XQ and He J: Cancer statistics in china, 2015. CA Cancer J Clin 66: 115-132, 2016.

4. Siegel RL, Miller KD and Jemal A: Cancer statistics, 2016. CA Cancer J Clin 66: 7-30, 2016.

5. Peeters M, Price T and Van Laethem JL: Anti-epidermal growth factor receptor monotherapy in the treatment of metastatic colorectal cancer: Where are we today? Oncologist 14: 29-39, 2009.

6. Li J, Zhang N, Zhang R, Sun L, Yu W, Guo W, Gao Y, Li M, Liu W, Liang $\mathrm{P}$, et al: CDC5L promotes htert expression and colorectal tumor growth. Cell Physiol Biochem 41: 2475-2488, 2017.

7. Kelly $\mathrm{C}$ and Cassidy J: Chemotherapy in metastatic colorectal cancer. Surg Oncol 16: 65-70, 2007.
8. Qi J, Yu Y, Akilli Ozturk O, Holland JD, Besser D, Fritzmann J, Wulf-Goldenberg A, Eckert K, Fichtner I and Birchmeier W: New Wnt/ $\beta$-catenin target genes promote experimental metastasis and migration of colorectal cancer cells through different signals. Gut 65: 1690-1701, 2016.

9. Hagan S, Orr MC and Doyle B: Targeted therapies in colorectal cancer-an integrative view by PPPM. EPMA J 4: 3, 2013.

10. Ou B, Zhao J, Guan S, Feng H, Wangpu X, Zhu C, Zong Y, Ma J, Sun J, Shen X, et al: CCR4 promotes metastasis via ERK/NF- $\kappa \mathrm{B} / \mathrm{MMP} 13$ pathway and acts downstream of TNF- $\alpha$ in colorectal cancer. Oncotarget 7: 47637-47649, 2016.

11. Valastyan S and Weinberg RA: Tumor metastasis: Molecular insights and evolving paradigms. Cell 147: 275-292, 2011.

12. Alberts SR, Horvath WL, Sternfeld WC, Goldberg RM, Mahoney MR, Dakhil SR, Levitt R, Rowland K, Nair S, Sargent DJ, et al: Oxaliplatin, fluorouracil, and leucovorin for patients with unresectable liver-only metastases from colorectal cancer: A north central cancer treatment group phase ii study. J Clin Oncol 23: 9243-9249, 2005.

13. Jove R: Preface: STAT signaling. Oncogene 19: 2466-2467, 2000.

14. Uchiyama T, Takahashi H, Endo H, Sugiyama M, Sakai E, Hosono K, Nagashima Y, Inayama Y, Wada K, Hippo Y, et al: Role of the long form leptin receptor and of the STAT3 signaling pathway in colorectal cancer progression. Int J Oncol 39: 935-940, 2011.

15. Kim HS, Kim T, Ko H, Lee J, Kim YS and Suh YG: Identification of galiellalactone-based novel STAT3-selective inhibitors with cytotoxic activities against triple-negative breast cancer cell lines. Bioorg Med Chem 25: 5032-5040, 2017.

16. Jiang C, Long J, Liu B, Xu M, Wang W, Xie X, Wang X and Kuang M: miR-500a-3p promotes cancer stem cells properties via STAT3 pathway in human hepatocellular carcinoma. J Exp Clin Cancer Res 36: 99, 2017.

17. Niwa Y, Kanda H, Shikauchi Y, Saiura A, Matsubara K, Kitagawa T, Yamamoto J, Kubo T and Yoshikawa H: Methylation silencing of SOCS-3 promotes cell growth and migration by enhancing JAK/STAT and FAK signalings in human hepatocellular carcinoma. Oncogene 24: 6406-6417, 2005.

18. Aggarwal BB, Kunnumakkara AB, Harikumar KB, Gupta SR, Tharakan ST, Koca C, Dey S and Sung B: Signal transducer and activator of transcription-3, inflammation, and cancer: How intimate is the relationship? Ann N Y Acad Sci 1171: 59-76, 2009.

19. Wang SW and Sun YM: The IL-6/JAK/STAT3 pathway: Potential therapeutic strategies in treating colorectal cancer (Review). Int J Oncol 44: 1032-1040, 2014.

20. Wang SW, Hu J, Guo QH, Zhao Y, Cheng JJ, Zhang DS, Fei Q, Li J and Sun YM: AZD1480, a JAK inhibitor, inhibits cell growth and survival of colorectal cancer via modulating the JAK2/STAT3 signaling pathway. Oncol Rep 32: 1991-1998, 2014.

21. Jiang P, Enomoto A, Jijiwa M, Kato T, Hasegawa T, Ishida M, Sato T, Asai N, Murakumo Y and Takahashi M: An actin-binding protein Girdin regulates the motility of breast cancer cells. Cancer Res 68: 1310-1318, 2008.

22. Gu F, Wang L, He J, Liu X, Zhang H, Li W, Fu L and Ma Y: Girdin, an actin-binding protein, is critical for migration, adhesion, and invasion of human glioblastoma cells. J Neurochem 131: 457-469, 2014.

23. Wang H, Misaki T, Taupin V, Eguchi A, Ghosh $\mathrm{P}$ and Farquhar MG: GIV/girdin links vascular endothelial growth factor signaling to Akt survival signaling in podocytes independent of nephrin. J Am Soc Nephrol 26: 314-327, 2015.

24. Dunkel Y, Ong A, Notani D, Mittal Y, Lam M, Mi X and Ghosh P: STAT3 protein up-regulates $\mathrm{G} \alpha$-interacting vesicle-associated protein (GIV)/Girdin expression, and GIV enhances STAT3 activation in a positive feedback loop during wound healing and tumor invasion/metastasis. J Biol Chem 287: 41667-41683, 2012.

25. Jin F, Liu C, Guo Y, Chen $\mathrm{H}$ and Wu Y: Clinical implications of Girdin and PI3K protein expression in breast cancer. Oncol Lett 5: 1549-1553, 2013.

26. Zhao L, Ma S, Liu Q and Liang P: Clinical implications of girdin protein expression in glioma. ScientificWorldJournal 2013: 986073, 2013.

27. Wang Y, Yuan L, Yang XM, Wei D, Wang B, Sun XX, Feng F, Nan G, Wang Y, Chen ZN and Bian H: A chimeric antibody targeting CD147 inhibits hepatocellular carcinoma cell motility via FAK-PI3K-Akt-Girdin signaling pathway. Clin Exp Metastasis 32: 39-53, 2015.

28. Wang C, Lin J, Li L and Wang Y: Expression and clinical significance of girdin in gastric cancer. Mol Clin Oncol 2: 425-428, 2014. 
29. Zhang YJ, Li AJ, Han Y, Yin L and Lin MB: Inhibition of Girdin enhances chemosensitivity of colorectal cancer cells to oxaliplatin. World J Gastroenterol 20: 8229-8236, 2014.

30. Ni W, Fang Y, Tong L, Tong Z, Yi F, Qiu J, Wang R and Tong X: Girdin regulates the migration and invasion of glioma cells via the PI3K-Akt signaling pathway. Mol Med Rep 12: 5086-5092, 2015.

31. Yu L, Sun Y, Li J, Wang Y, Zhu Y, Shi Y, Fan X, Zhou J, Bao Y, $\mathrm{Xiao} J$, et al: Silencing the Girdin gene enhances radio-sensitivity of hepatocellular carcinoma via suppression of glycolytic metabolism. J Exp Clin Cancer Res 36: 110, 2017.

32. Schonberg DL, Lubelski D, Miller TE and Rich JN: Brain tumor stem cells: Molecular characteristics and their impact on therapy. Mol Aspects Med 39: 82-101, 2014.
33. Chang KC, Wu MH, Jones D, Chen FF and Tseng YL: Activation of STAT3 in thymic epithelial tumours correlates with tumour type and clinical behaviour. J Pathol 210: 224-233, 2006.

34. Murray PJ: The JAK-STAT signaling pathway: Input and output integration. J Immunol 178: 2623-2629, 2007.

35. Kowshik J, Baba AB, Giri H, Deepak Reddy G, Dixit M and Nagini S: Astaxanthin inhibits JAK/STAT-3 signaling to abrogate cell proliferation, invasion and angiogenesis in a hamster model of oral cancer. PLoS One 9: e109114, 2014.

36. Peng HX, Wu WQ, Yang DM, Jing R, Li J, Zhou FL, Jin YF, Wang SY and Chu YM: Role of B7-H4 siRNA in Proliferation, Migration, and Invasion of LOVO colorectal carcinoma cell line. Biomed Res Int 2015: 326981, 2015. 